\title{
28 Research Square \\ Changes in Chinese Patients' Trust in Doctor:a Systematic Review and Meta-Analysis
}

Yuting LIU

Shanghai Normal University

Pei WANG ( $\nabla$ wangpei1970@163.com )

East China Normal University https://orcid.org/0000-0002-6309-2366

\section{Research}

Keywords: patients' characteristics, medical policy, patients' trust, meta-analysis

Posted Date: April 30th, 2021

DOI: https://doi.org/10.21203/rs.3.rs-470437/v1

License: (9) This work is licensed under a Creative Commons Attribution 4.0 International License. Read Full License 


\section{Abstract}

Background: To understand how patient's trust has changed over time in China and explore the influencing factors of the changes.

Methods: Databases were systematically searched from inception to Jan 1, 2020 for studies of patient's trust in China investigating the change of the patient's trust over time and the factors which influence the trust.

Results: The cross-temporal meta-analysis results showed that the total trust, benevolence trust and technical competence trust of Chinese patients decreased rapidly across the year of data collection. The related meta-analysis results showed that trust and patient demographic variables have a weak but significant correlation (gender: $r=0.032 ; 95 \% \mathrm{Cl} 0.012,0.052 ; p=0.002$; age: $r=0.079 ; 95 \% \mathrm{Cl} 0.047$, $0 \cdot 111 ; p<0.001$; education: $r=0.092 ; 95 \% \mathrm{Cl} 0.054,0 \cdot 131 ; p<0.001)$. The medical policy stage and patient type had a significant influence on changes of trust.

Conclusion: Patients' trust in doctors have declined with increasing years, and farmer-friendly policy, conflicts and individuals' characteristics influence patients' trust.

Practice implication: Chinese government should attach importance to the public welfare-oriented policies. Medical institutions need pay more attention to the diverse trust levels of different patient groups and strengthen the training of doctors' benevolence skills.

\section{Introduction}

Trust, the core of the harmonious doctor-patient relationship, is related to the process and the final results of medical diagnosis and treatment. ${ }^{1}$ A majority of the existing empirical and theoretical research in this area has shown that the patient who trusts the doctor has more satisfaction at the treatment, more beneficial health behaviors and higher intention to comply. ${ }^{2-4}$ In contrast, due to mistrust, the patient suspects the doctor's motivation and even treats the therapeutic staff aggressively. ${ }^{5}$ During the process, necessary self-protection measures by the doctor lead to conservative medical treatment and difficulty of communication. ${ }^{6}$ Therefore, a good patient's trust is not only the basis of effective treatment but also a vital link to build a harmonious doctor-patient relationship.

\section{Patient's trust}

Patient's trust is the willingness of the patient to be vulnerable to the actions of the doctor based on the expectation that the doctor will perform a particular action important to the patient, irrespective of the ability to monitor or control that the doctor. ${ }^{7,8}$ Due to the painful injury of the disease and the asymmetry of information in the medical process, the patient trust their doctor who can bring them recovery. ${ }^{9-12}$ 
With regard to the types of the patient's trust, Hall classified it into two categories: technical competence trust, which is qualified practice skills to make correct decisions and avoid mistakes, and benevolence trust, which is interpersonal and communication skills to care the patient's interests and tell the truth. ${ }^{8}$ Besides, some researchers have proposed that patient's trust consists of affective trust and cognitive trust. $^{13,14}$ Sun and Wang conceptualized patient's trust as three-dimensional: interpersonal trust, intergroup trust and institutional trust. ${ }^{15-17}$ We adopted the Hall's classification in this study which was used by the most researchers. ${ }^{2,8}$

There are a variety of the patient's trust scales, especially in the developed countries. In 1990, Anderson explored the first English-language scale for the systematic assessment of patient trust which has good reliability and established a standard for such measurement tools in the future. ${ }^{18}$ Since then, many researchers have begun systematic studies on patient's trust scales, such as the Safran Primary Care Scale, ${ }^{19}$ the Kao Patient Trust Scale, ${ }^{20}$ and the Wake Forest Physician Trust Scale (WFPTS). ${ }^{8}$ However, the study of the patients' trust scale in China is still in the initial stage, because most researchers used the Chinese adaptation of the WFPTS to assess the patients' trust in China, rather than designing questionnaires based on the actual state of China. ${ }^{2,21-23}$

\section{Patient's trust in China}

At present, the status of the patient's trust in the world is still unknown. The global comparisons of trust attitudes around the world suggested that the share of people reporting to trust others in China is much higher than that in most developed countries. ${ }^{24}$ However, in the past decade, doctor-

patient conflicts occurred frequently and the negative reports about the relationship between doctors and patients have been overwhelming in China, which led to the original harmonious doctor-patient relationship has been becoming tense. ${ }^{12}$

Before 2009, the patient's trust in China was high. ${ }^{25}$ However, the results of several studies in recent years have shown that the patient's trust was at a low level. ${ }^{26-30}$ Meanwhile, after comparing the level of interpersonal patient's trust between China in 2011 and 2016, it was found that the trust in 2016 was significantly lower than that in $2011 .{ }^{23}$ These findings have prompted calls for increased attention to the patient's trust in China.

In 2002, Chinese researchers started exploring doctor-patient trust from the perspective of ethics. There is quite more theoretical research on the concept, model construction, evolution process and evaluation system, while few empirical studies focus on improving patient's trust. ${ }^{31}$ As far as the research content is concerned, the current empirical research of patient's trust has been lagging behind the investigation of the characteristics and overall situation of both doctors and patients, which lacks in-depth medical research with the dynamic and systematic construction. With regard to the measurement tools, we lack a universal scale that is fully applicable to the Chinese patient's trust research. These studies in China, which should have supported the government in improving patient's trust, are still in their infancy. 
Therefore, it is urgent for Chinese organizations and researchers to take better measures to improve the patient's trust.

\section{Factors influencing patient's trust in China}

In order to improve the patient's trust, we need to explore the main influencing factors of the trust in China. Some researchers summarize the antecedents of the patient's trust, including social environment, treatment situations and individual characteristics. ${ }^{12}$ At present, few research studies in China focus on treatment situations and doctors' characteristics. Therefore, we summarized the influencing factors of the patient's trust from two aspects: patients' characteristics and social environment.

\section{Patients' characteristics}

A majority of the existing empirical researches in this area have begun to focus on the influence of patients' characteristics. ${ }^{12,22,32}$ From the perspective of patient demographic variables which were studied most, some research pointed out that female patients and the patient with the same gender as the doctor trust doctors more; ${ }^{33,34}$ some studies found that patient age is negatively related to patient's trust $^{33}$ but some evidence show the opposite result. ${ }^{1,22,34}$ Additionally, a positive correlation between patients with different educational background and the patient's trust was also demonstrated. ${ }^{35} \mathrm{However}$, the relationship among patient gender, age, education and trust are controversial, since some studies found no clear correlation between them, ${ }^{36-38}$ and some research investigated that patient gender, age, education may influence the patient's trust. ${ }^{32-34}$ Additionally, little evidence showed that these factors such as occupation, social class, economic status, and family background seem to affect patient's trust. ${ }^{12,39-41}$ Inpatients, rural patients and the patient with the serious illness also have a high level of trust. $^{25,42,43}$

\section{Social environment}

The formation of patient's trust depends not only on patients' characteristics, but also on social factors such as government, organizations and media. Among them, the changes of China's medical policy and the growing number of doctor-patient conflicts have the greatest impact on the patient's trust. ${ }^{44-46}$

In 1949-1977, the doctor-patient relationship was good. People enjoyed free medical services and high public welfare. However, a market-oriented operation adopted in the healthcare industry led to the fragile doctor-patient relationship in 1978-2002. Since 2003, in order to better realize the transition from marketoriented operations to public welfare-oriented operations for the medical industry, the State Council of China launched a new round of medical reform programs in 2009, which aimed to establish and develop the basic coverage system for urban and rural residents. Especially, with the incessant deepening of the healthcare industry reform between 2013 and 2017, a package of measures has been established, including the hierarchical medical system, lowering drug prices, medical insurance fee system, promoting the reform of public hospitals, and equalization of basic public health service. ${ }^{44}$ The farmer-friendly 
policy which involved in the interests of a majority of the people may promote the trust level of the public. $^{24,45}$

However, in recent years, China's doctor-patient conflicts occurred frequently. Statistics from the National Health and Family Planning Commission of China (2001-2016) showed that the number of vicious incidents caused by doctor-patient conflicts was 4,914 in 2001, increasing to over 8,000 in 2004, and nearly 10,000 in 2006. In 2016, the number of conflicts between doctors and patients was $20,833 .{ }^{46-49}$ Violence against the medical personnel has become a terrible wound in Chinese society. ${ }^{50}$ These conflicts exacerbated the mistrust between doctors and patients, ${ }^{51}$ which is also the main reason for the deterioration of the doctor-patient relationship. ${ }^{52}$

Although we summarized these important factors on patient's trust, evidence about the role of these influencing factors in the patient's trust is still unknown. Therefore, it is essential for China to understand the changing trend of patient's trust in these years, explore the effect of the influencing factors of the changes and determine the relationship between some patient characteristics and patient's trust. To date, to our knowledge, there is no studies comprehensively examining the status of patient's trust, including the status, influencing factors, existing problems and future research directions of Chinese patient's trust. To address this research gap, we conducted a systematic review and a cross-temporal meta-analysis to explore whether patients' trust to doctors has changed over the years. ${ }^{53-55}$ We also investigated whether the policy stage, the type of patients, and the scales differentially influence the trust. Especially, about the patient type, most studies used $t$ test and $F$ test to analyze the relationship between some patient characteristics (gender, age and education) and patient's trust, rather than separately exploring the trust value of different gender, age and education. In order to clarify the influence of these patient characteristics on patient's trust, we conducted a related meta-analysis to examine the association between patient demographic variables (gender, age, and education) and patient's trust.

\section{Methods}

\section{Search strategy and selection criteria}

In accordance with the PRISMA guidelines ${ }^{56}$, we began our systematic literature search for studies by some widely used academic databases from database inception to Jan 1, 2020, including Wanfang, CNKI, Google Scholar, PubMed, Web of Science, the Social Sciences Citation Index, Chinese Doctoral Dissertations Full-Text Database, and Chinese Master's Dissertations Full-Text Database. Studies were located by employing combinations of the following search terms with no language restrictions: China, Chinese, trust, physician, doctor, and patient.

We included studies using quantitative data to assess the trust of Chinese patients or the association between patients' trust and patients' demographic variables. We included studies in which sufficient data were reported (Mean, Standard Deviation and Sample size; $r$ value or $F, t$ or $\chi^{2}$ value that can be converted to $r$ wherever possible). ${ }^{57}$ We excluded studies of case vignettes, interviews, reviews and theory. We 
required studies to measure interpersonal and intergroup trust to doctors with a valid, reliable and established trust questionnaire. Papers from which data were extracted are marked with an asterisk in the reference section.

Two reviewers (Y.L. and P.W.) independently screened each abstract and full-text article, and excluded those that were not ineligible. Discrepancies about inclusion of full-text reports were resolved by discussion. The study protocol is available online.

\section{Data analysis}

We designed two data extraction tables to extract data on the average patient's trust score (including total trust, benevolence trust and technical competence trust), sample size, publication year and data collection year for the cross-temporal meta-analysis (table 1), and the $r$ value (the association between trust and gender, age, education), sample size, publication year and data collection year for the related meta-analysis (table 2) (appendix). Additionally, the year of data collection, which indicated participants' birth cohort, was coded one year prior to submitting the dissertation and two years prior to publication unless another date was reported in the article. ${ }^{58-60}$ If data from two studies were reported in one publication, we extracted data from each study independently. Data extraction was conducted by two reviewers (Y.L. and P.W.).

Meanwhile, the results of the cross-temporal meta-analysis will be affected by the characteristics of participants. ${ }^{54,61}$ So, patient type was also recorded in the first code. In order to further determine the effect of medical policy stages on patient's trust, combined with the classification of medical policy stages ${ }^{44}$ we further divided the data collection years into two stages in view of different process of new medical reform, one is the early stage of reform (2008-2012), the other is the later stage which developed comparatively mature (2013-2017). Besides, less literature used the same scale (only half of the studies use the Wake Forest Patient Trust Scale), in order to prevent publication bias due to the missing data, we tried to include researches that using valid self-created and adapted questionnaires with similar research content while ensuring the quality of literature, and conducted subgroup analysis on these scales in the results. Thus, we also recorded medical policy stages and patient's trust measurement dimensions in two sheets.

Risk of bias was assessed by two reviewers (Y.L. and P.W.) using the Newcastle-Ottawa Quality Assessment scale for observational study designs. ${ }^{62}$ The quality tiers used for categorization of studies as 'Low', 'Intermediate' and 'High' quality were presented in the appendix.

In the cross-temporal meta-analysis, we conducted the weighted regression analysis to explore the change in the patient's trust (including total trust, benevolence trust and technical competence trust) over time. Then, we did moderator analysis on medical policy stages, patient type, and patient's trust measurement dimensions; In the related meta-analysis, we measured heterogeneity using $R$ statistic and assessed publication bias by funnel plots and Egger test in separate models. Then, we carried out the 
meta-analysis to assess correlations between patient's trust and patient demographic variables (gender, age, and education), and performed subgroup analysis on medical policy stages and patient's trust measurement. All statistical analyses were done using Excel 2018, SPSS $24 \cdot 0$ and Stata 14.0.63

\section{Role of the funding source}

The funder of the study had no role in study design, data collection, data analysis, data interpretation, or writing of the report. The corresponding author had full access to all the data in the study and Y.L. and P.W. had final responsibility for the decision to submit for publication.

\section{Results}

\section{Search results and quality assessment}

Our search strategy identified 544 articles, of which 40 met eligibility criteria for full-text review (figure 1). Among the 40 studies that were published between 2009 and 2019 with 48,376 participants, 33 studies with 45,711 participants were used to conduct the cross-temporal meta-analysis, $2,21-23,25-29,32,34,35,37,38,41$ 43,64-79 and 17 studies with 9,976 participants were used to conduct the related meta-analysis. 2,21,26,32,34$38,65,71,80-85$ of the 40 qualitative studies, 28 were deemed to be of 'high' quality and 12 were deemed to be of 'Intermediate' quality according to our evaluation by using the Newcastle-Ottawa Quality Assessment scale. No studies were excluded on the basis of quality.

\section{Cross-temporal meta-analysis}

\section{The trends in different types of patient's trust}

According to the shape of the Scatter chart (figure 2,3), a generally linear decline in patient's trust from 2008 to 2017 and two large fluctuations separately at 2009 in figure 2 and 2013 in figure 3 were shown. In order to clarify the differences in trust between years, we conducted variance analysis in total trust, benevolence trust and technical competence trust. The result showed that patient's trust in $2009(M=$ $4 \cdot 154, S D=0.127)$ was significantly higher than that in $2008(M=3.316, S D=0.470)(t=-3.504, p=$ $0.017)$ in total trust, and patient's trust in $2013(M=3.049, S D=0.035)$ was significantly lower than that in $2011(M=4 \cdot 142, S D=0.371)(t=3.941, p=0.029)$ in benevolence trust.

\section{Correlations between trust and years}

Since these patients' trust levels were all showing a downward trend after 2009 , it was more meaningful to analyze the correlations from 2009 to 2017. When sample size was weighted, the total trust scores has a significant correlation with year of data collection, $\beta=-0 \cdot 445, p=0 \cdot 001$, the benevolence trust scores also has a significant correlation with year of data collection, $\beta=-0.044, p=0.034$, and the correlation between technical competence trust and year of data collection was $-0.390, p=0.066$. These suggested that patients' trust scores decreased over time. 
To calculate the magnitude of change in all trust scores, we predicted the mean scores of the first (2009) and last year (2017) of the included studies by conducting the weighted regression analysis with patient's trust scores and year of data collection as the dependent and independent variables and averaged all the standard deviations reported in the studies through calculating the average standard deviation. ${ }^{86,87}$ The regression equation is: $y=B x+C, y$ is the average score of various types of trust, $B$ is the partial regression coefficient, $\mathrm{x}$ is the year of data collection, and $\mathrm{C}$ is a constant. The regression equations for total trust, benevolence trust, and technical competence trust were: $\mathrm{y}=-0.078 \mathrm{x}+159 \cdot 846(p=0.010), \mathrm{y}=$ $-0.080 x+164.344(p=0.027)$, and $y=-0.065 x+134.899(p=0.054)$. The mean of total trust decreased by 0.624 , from 3.144 in 2009 to 2.520 in 2017 and scores decreased by 0.845 standard deviations from 2009 to 2017 , which is $d=0.845$; The mean of benevolence trust decreased by 0.640 from 3.624 in 2009 to 2.984 in 2017 and scores decreased by 0.982 standard deviations, that is $d=0.982$. The mean of technical competence trust decreased by 0.520 from 4.314 in 2009 to 3.794 in 2017 and scores decreased by 0.590 standard deviations, that is $d=0.590$. According to Cohen's interpretation of effect size, ${ }^{88} d=0.80$ is large, and $d=0.50$ is classified as moderate. Therefore, $d=0.845$ and $d=0.982$ should be regarded as a large effect size, $d=0.590$ should be considered a moderate effect size. The above results showed that the levels of the total trust and benevolence trust in Chinese patients declined rapidly across the years of data collection.

\section{Moderator analysis}

The results indicated that the medical policy stage had a significant influence on trust, and patient's trust questionnaires had no significant effect on the relationship between trust and year (table 3). All trust values of the previous stage were significantly higher than the later stage. What's more, in the patient type, it was found that inpatients had higher results in total trust than outpatients significantly and rural patients had higher trust levels than urban patients by using independent $t$-test.

\section{Table 1. Moderator analyses}




\begin{tabular}{|c|c|c|c|c|}
\hline Trust & Moderator & $M \pm S D$ & $t / F$ & $p$ \\
\hline & \multicolumn{4}{|l|}{ Medical policy stages } \\
\hline \multirow[t]{2}{*}{ Total } & Stage I & $3 \cdot 852 \pm 0 \cdot 086$ & $16 \cdot 708$ & $<0.001$ \\
\hline & Stage II & $3 \cdot 457 \pm 0 \cdot 044$ & & \\
\hline \multirow[t]{2}{*}{ benevolence } & Stage I & $4 \cdot 093 \pm 0 \cdot 226$ & $7 \cdot 021$ & 0.015 \\
\hline & Stage II & $3 \cdot 475 \pm 0 \cdot 056$ & & \\
\hline \multirow[t]{3}{*}{ technical competence } & Stage I & $4 \cdot 192 \pm 0 \cdot 218$ & $9 \cdot 622$ & 0.005 \\
\hline & Stage II & $3 \cdot 495 \pm 0 \cdot 053$ & & \\
\hline & Patient Types & & & \\
\hline \multirow[t]{2}{*}{ Total } & Inpatient & $3 \cdot 691 \pm 0 \cdot 083$ & $9 \cdot 089$ & 0.007 \\
\hline & Outpatient & $3 \cdot 297 \pm 0 \cdot 101$ & & \\
\hline \multirow[t]{2}{*}{ benevolence } & Inpatient & $3 \cdot 722 \pm 0 \cdot 098$ & $2 \cdot 278$ & $0 \cdot 152$ \\
\hline & Outpatient & $3 \cdot 406 \pm 0 \cdot 185$ & & \\
\hline \multirow[t]{2}{*}{ technical competence } & Inpatient & $3 \cdot 755 \pm 0.080$ & $0 \cdot 207$ & 0.656 \\
\hline & Outpatient & $3 \cdot 677 \pm 0 \cdot 152$ & & \\
\hline \multirow[t]{3}{*}{ total } & Urban patient & $3 \cdot 726 \pm 0 \cdot 112$ & 0.304 & 0.605 \\
\hline & Rural patient & $3 \cdot 815 \pm 0 \cdot 116$ & & \\
\hline & Scale Types & & & \\
\hline \multirow[t]{2}{*}{ Total } & Wake Forest Patient Trust Scale & $3 \cdot 456 \pm 0 \cdot 065$ & 3.030 & 0.088 \\
\hline & Other Trust Questionnaires & $3 \cdot 610 \pm 0 \cdot 060$ & & \\
\hline \multirow[t]{2}{*}{ benevolence } & Wake Forest Patient Trust Scale & $3 \cdot 501 \pm 0 \cdot 067$ & $0 \cdot 146$ & 0.706 \\
\hline & Other Trust Questionnaires & $3 \cdot 568 \pm 0 \cdot 163$ & & \\
\hline \multirow[t]{2}{*}{ technical competence } & Wake Forest Patient Trust Scale & $3 \cdot 492 \pm 0 \cdot 063$ & $3 \cdot 189$ & 0.088 \\
\hline & Other Trust Questionnaires & $3 \cdot 788 \pm 0 \cdot 153$ & & \\
\hline
\end{tabular}

\section{Related meta-analysis}

\section{Heterogeneity}

The random effect model and the fixed effect model are two main models in meta-analysis. ${ }^{89}$ Higgins believed that $P$ is $25 \%, 50 \%$, and $75 \%$, which means low heterogeneity, medium heterogeneity, and high heterogeneity, respectively. ${ }^{90}$ Hedges proposed that the random effect model is more appropriate when 
the Heterogeneity test result is significant, otherwise, the fixed effect model is selected. ${ }^{89}$ Combined with the above two criteria, the heterogeneity tests were conducted on the meta-analysis data of the relationship between patients' gender, age, education and patient's trust. The results showed that the effect size of the gender data was homogeneous but the effect size of the age and education data were heterogeneous. Therefore, it is appropriate for the gender data to choose the fixed-effect model on the grounds that $31.5 \%$ of the observed variation in the gender data was caused by the real difference between the two, and yet the random effect model was suitable for the age and gender data due to $50.3 \%$ and $58.8 \%$ observed variation (table 2). ${ }^{91}$

\section{Publication bias}

Publication bias tests were performed by using a funnel plot and Egger test. ${ }^{92}$ From the funnel plot, the studies involved in this study were distributed evenly on both sides of the total effect. According to the Egger test, ${ }^{93}$ there was no publication bias for gender $(t=1 \cdot 73, p=0 \cdot 104)$ and education $(t=2 \cdot 07, p=$ $0.061)$. Although there was publication bias for age $(t=2.50, p=0.025)$, the number of missing studies was estimated to be 5 after 5 iterations with the Linear method, and 5 similar studies were added around the center of the funnel plot at the opposite mirror position by the trim-and-fill analysis. ${ }^{94}$ Then, the metaanalysis was performed again using the random effects model. The new combined effect index was 0.055 ([95\% Cl 0.024-0.085]; $p<0.001$ ). Because the combined effect index before trimming was 0.079 ([95\% Cl 0.047-0.111]; $p<0.001)$, and there was not much difference between the two combined results. Therefore, it could be considered that although there was a slight publication bias in the age data, the results were still valid (appendix). ${ }^{95}$

\section{Association between trust and patient demographic variables}

Across all outcomes, we found a small but significant correlation between trust and patient demographic variables (gender: $r=0.032$ [95\% Cl 0.012-0.052]; $p=0.002$; age: $r=0.079$ [95\% Cl 0.047-0.111]; $p<0.001$; education: $r=0.092$ [95\% Cl 0.054-0.131]; $p<0.001$ ) (table 2 and figure 4-6 which shows all forest plots).

\section{Table 2. Associations between patient's trust and patient demographic variables}

\begin{tabular}{|c|c|c|c|c|c|c|}
\hline $\begin{array}{l}\text { patient demographic } \\
\text { variables }\end{array}$ & $\begin{array}{l}\text { Nof studies } \\
\text { (patients) }\end{array}$ & $Q(d f)$ & $R$ & $r$ & $95 \% \mathrm{Cl}$ & $z$ \\
\hline Gender & 17 (9771) & $23 \cdot 35(16)$ & $31 \cdot 5 \%$ & 0.032 & $\begin{array}{l}0.012, \\
0.052\end{array}$ & $3 \cdot 17^{\star \star}$ \\
\hline Age & 16 (9592) & $\begin{array}{l}30 \cdot 15(15) \\
\star\end{array}$ & $50 \cdot 3 \%$ & 0.079 & $\begin{array}{l}0.047 \\
0.111\end{array}$ & $4 \cdot 89^{\star \star \star \star}$ \\
\hline Education & 14 (7948) & $31 \cdot 52(13)$ & $58.8 \%$ & 0.092 & $\begin{array}{l}0.054 \\
0.131\end{array}$ & 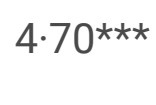 \\
\hline
\end{tabular}

Note. ${ }^{\star} p<0.05,{ }^{\star \star} p<0 \cdot 01,{ }^{* \star *} \mathrm{p}<0 \cdot 001 ; r=$ correlation, $C l=$ confidence interval. 


\section{Subgroup analysis}

Stratified analysis showed some variation in associations between gender, age and trust when studies were analyzed at different medical policy stages. In the medical policy stage 1, the results of association between gender, age and trust were insignificant. However, in the stage 2 , the results of these association were significant, which indicated that women and the seniors report more trust to their doctors. No variation in associations between patient demographic variables and trust when different trust questionnaires were used (table 3).

Table 3. Associations between patient's trust and patient demographic variables stratified according to the Medical policy stages and Trust Questionnaire. 


\begin{tabular}{|c|c|c|c|c|c|c|}
\hline $\begin{array}{l}\text { Patient } \\
\text { Variable }\end{array}$ & Subgroup & $\begin{array}{l}\text { Nof studies } \\
\text { (patients) }\end{array}$ & $r$ & $95 \% \mathrm{Cl}$ & $Z$ & $p$ \\
\hline \multirow[t]{6}{*}{ Gender } & Medical policy stages & & & & & \\
\hline & Stage I & $5(1406)$ & 0.033 & $\begin{array}{l}-0.019 \\
0.085\end{array}$ & $1 \cdot 25$ & $0 \cdot 213$ \\
\hline & Stage II & $12(8365)$ & 0.032 & $\begin{array}{l}0.010 \\
0.053\end{array}$ & $2 \cdot 92$ & 0.004 \\
\hline & Trust Questionnaire & & & & & \\
\hline & $\begin{array}{l}\text { Wake Forest Patient } \\
\text { Trust Scale }\end{array}$ & $9(6222)$ & 0.027 & $\begin{array}{l}0.002 \\
0.051\end{array}$ & $2 \cdot 11$ & 0.035 \\
\hline & $\begin{array}{l}\text { Other Trust } \\
\text { Questionnaires }\end{array}$ & 8 (3549) & 0.041 & $\begin{array}{l}0.009 \\
0.074\end{array}$ & $2 \cdot 47$ & 0.013 \\
\hline \multirow[t]{6}{*}{ Age } & Medical policy stages & & & & & \\
\hline & Stage I & $5(1611)$ & 0.076 & $\begin{array}{l}-0 \cdot 006 \\
0 \cdot 159\end{array}$ & $1 \cdot 82$ & 0.069 \\
\hline & Stage II & $11(7981)$ & 0.079 & $\begin{array}{l}0 \cdot 047 \\
0 \cdot 112\end{array}$ & $4 \cdot 51$ & $<0.001$ \\
\hline & Trust Questionnaire & & & & & \\
\hline & $\begin{array}{l}\text { Wake Forest Patient } \\
\text { Trust Scale }\end{array}$ & $7(5560)$ & 0.079 & $\begin{array}{l}0.033 \\
0.142\end{array}$ & $3 \cdot 73$ & 0.002 \\
\hline & $\begin{array}{l}\text { Other Trust. } \\
\text { Questionnaires }\end{array}$ & 9 (4032) & 0.075 & $\begin{array}{l}0.036 \\
0.115\end{array}$ & $3 \cdot 73$ & $<0.001$ \\
\hline \multirow[t]{6}{*}{ Education } & Medical policy stages & & & & & \\
\hline & Stage I & $4(1204)$ & $0 \cdot 146$ & $\begin{array}{l}0.027 \\
0.264\end{array}$ & $2 \cdot 41$ & $0 \cdot 016$ \\
\hline & Stage II & $10(6744)$ & 0.069 & $\begin{array}{l}0.035 \\
0.085\end{array}$ & $4 \cdot 72$ & $<0.001$ \\
\hline & Trust Questionnaire & & & & & \\
\hline & $\begin{array}{l}\text { Wake Forest Patient } \\
\text { Trust Scale }\end{array}$ & $8(5838)$ & $0 \cdot 111$ & $\begin{array}{l}0.050 \\
0 \cdot 172\end{array}$ & $3 \cdot 56$ & $<0.001$ \\
\hline & $\begin{array}{l}\text { Other Trust } \\
\text { Questionnaires }\end{array}$ & $6(2110)$ & 0.072 & $\begin{array}{l}0.030 \\
0.115\end{array}$ & $3 \cdot 34$ & 0.001 \\
\hline
\end{tabular}

Note. $r=$ correlation; $\mathrm{Cl}=$ confidence interval.

\section{Discussion}


Our research conducted the cross-temporal meta-analysis on patients' trust over the past ten years and found patients' total trust, benevolence trust and technical competence trust to doctors have declined within these years. This result was in agreement with the findings of a comparison of interpersonal trust levels in 2011 and 2016. ${ }^{23}$

The main reasons for the decline in patient's trust in the past decade are as follows. Doctor-patient disputes could exacerbate doctor-patient mistrust. ${ }^{51}$ According to the National Health and Family Planning Statistical Yearbook 2017, the number of medical disputes handled by the courts in 2016 was twice that in 2006; the relevant statistics from the national health department (2016) also showed that the number of incidents where medical services were disrupted by patients increased by five times compared with 2001. 46-48 Meanwhile, the doctor's negative image was fabricated from 2011 to 2015 due to the media's unreasonable reporting framework on medical disputes, which has had a greater impact on patient's trust. ${ }^{96,97}$ What's worse, the news 'labeling', onblur and irrational public opinions further pushed the doctor-patient relationship into the abyss. ${ }^{98-100}$

More importantly, different stages of medical policy had a great impact on trust. China's medical system entered the stage of marketization after 1978: the government categorized hospitals as private ownership, excessive market competition led to the gradual decrease of government health investment, the healthcare service gap between urban and rural expanded, and patient medical costs rapidly increased. ${ }^{44}$ Among them, marketization had a restraining effect on trust. ${ }^{101}$ Therefore, in 2009, a new round of medical reform was launched to reverse marketization by increasing public welfare and improving the medical insurance system. From the overall trust value in 2009 (Figure 2), it can be seen that this measure has had some effects on trust. However, the development of market rules was still insufficient to fully protect the interests of patients. ${ }^{102}$ In particular, from the changes of benevolence trust and technical competence trust, it can be seen that the trust of patients in China has declined significantly before 2013 . After 2013 , a series of measures were vigorously carried out to strengthen the construction of public service system, such as improving the primary care system, increasing grassroots medical institutions, optimizing the allocation of medical resources, strengthening medical supplies regulation, improving the pharmaceutical distribution system, and building a universal health care system. ${ }^{44}$ According to the data of the National Health and Family Planning Commission of the PRC, the new rural cooperative medical insurance accounted for nearly $95 \%$, and the government and medical insurance beard 299.5 billion yuan (71.1\%) of China's total health expenditure in 2016, which to some extent reduced the burden of patients, so patient's trust has been stable. It is worth noting that though the Chinese government has invested heavily in the medical industry, new healthcare reform is still faced with numerous difficulties and challenges: the dislocation profit model, the rising of drugs, and the burdensome medical insurance fund. Thus, the trust value of the later stage (2013-2017) was still low. White Paper: Medical and Health Services in China pointed out that the contradiction among China's current series of policy, public health needs and the coordinated development of the economy and society was still unsuitable and prominent. During the outbreak of novel coronavirus (2019-nCoV), a lot of emotional construction aimed to improve the doctor-patient relationship was carried out throughout the 
country. However, serious violent incidence between doctors and patients still occurred, since the medical policy could not meet the needs of patients.

Additionally, our results also showed that the benevolence trust decreased rapidly across the years. The possible reasons are as follows: The rigid behavior and the dehumanizing medical attitude of the doctor may affect the patient's perception of benevolence and trust, ${ }^{103,104}$ In addition, excessive medical treatment has been widespread in China in recent years: Doctors put patients on drugs excessively in order to avoid medical treatment risk or to get more pharmaceutical rebates. ${ }^{44} \mathrm{It}$ is difficult for the patient to clarify the motivation of the doctor for excessive medical treatment, which leads to suspicion of doctor's professional ethics; ${ }^{105,106}$ Furthermore, high medical costs and fee-for-service systems also affect benevolent trust. Since Chinese patients must pay separately at each step of the medical treatment process (consultation, diagnosis, intravenous drip, medication, etc.), that is, money seems to be emphasized throughout all medical processes, this payment term is likely to increase patients' distrust in doctors' benevolence. ${ }^{107}$

\section{Patient's characteristics influence trust}

The results of the related meta-analysis showed that patients' gender, age, and education were significantly related to patients' trust, though these correlations were low $(r$ gender $=0.032, r$ age $=0.079, r$ education $=0.092) .{ }^{88}$ of particular relevance to the trust do-main, women are characterized by a desire to form and maintain relationships compared to men. ${ }^{108,109}$ So, women are more likely to trust their doctor. With regard to age, the older contact doctors more frequently and are more dependent on doctors. Thus, the senior reported to have more trust to the doctor. Lastly, the evidence suggests that education is one of the strongest factors associated with social capital in general and greater trust in particular: the better educated individuals are, the higher social status they have, the more likely they are to have high levels of trust. ${ }^{110-112}$ In addition, the medical policy stage, as a moderator variable, had positive effects on the association results of gender and age, which indicated that the construction of the public service system was positively promoting the relationship between gender, age and trust to a certain extent. Studies have demonstrated that the female and the senior have made greater use of basic public health services in recent years. ${ }^{113}$ It can be seen that the construction of the public service system has brought benefits to relatively vulnerable groups and promoted their perception of trust.

According to the results of the moderator analysis in the cross-temporal meta-analysis, the study also found that inpatients had significantly higher trust levels (total trust, benevolence trust and technical competence trust) than outpatients. This result was in line with the findings of Tam and Jiang. ${ }^{25,43}$ Based on Service Encounter Theory, ${ }^{114}$ the generation of trust has a cognitive basis, and the increased interaction between the doctor and the patient is conducive to the patient's trust. ${ }^{102}$ Compared with outpatients, inpatients have longer contact time with doctors, so they are more familiar with their doctors, and doctors also have a more detailed understanding of inpatients. ${ }^{68,102,115}$ What's more, according to Interdependency Theory, ${ }^{116}$ two-way dependence situations and high levels of patient dependence 
promote patients' trust. ${ }^{117}$ In general, the conditions of inpatients are more serious than those of outpatients, thus inpatients rely on doctors more and give them more hope for health. ${ }^{25}$ So, the inpatient has a higher level of trust. For the same reason, rural patients' trust in doctors was more than urban patients' trust. Some studies have investigated the differences in the doctor-patient relationship between urban and rural areas, and found that rural patients usually seek medical treatment in rural health clinics or village clinics. ${ }^{42}$ Villagers are familiar with their doctors, and convenient to seek medical treatment. However, municipal hospitals have fewer communication opportunities and higher costs. As a result, rural patients have higher levels of trust in doctors.

\section{Implications and limitations}

The comprehensive scope of this review on the patient's trust in China is a strength, since we combined the cross-temporal meta-analysis and the related meta-analysis to analyze the status of the patient's trust and the effect of the influencing factors, with low publication bias. However, this study has limitations. Our original systematic search did not include literature published in 2010, since there was no data for that year, and thus it might affect the results. Also, the number of researches included in this review was not large. However, the quality and data of the included studies were sufficient to explore the changing trends of patient's trust.

In Summary, in the past ten years (2008-2017), the trust of Chinese patients has shown a downward trend, and the benevolence trust has fallen fastest. Medical policy, doctor-patient disputes and patients characteristics influence the trust. Therefore, our government should attach importance to the public welfare-oriented policies and formulate relevant policies to resolve doctor-patient conflicts, medical institutions need to pay more attention to the diverse trust levels of different patient groups and strengthen the training of doctors' benevolence skills, and researches ought to improve measurement tools which is applicable to the Chinese patient's trust research and conduct more in-depth medical researches to improve the patient's trust.

\section{Declarations}

\section{Ethical Approval and Consent to participate}

This study was approved by the local ethics committee of Shanghai Normal University and was conducted in accordance with the Declaration of Helsinki (2013). All participants were informed before the investigation began.

\section{- Conflict of Interest}

The authors declare that they have no conflict of interest.

\section{- Consent for publication}

he authors both agree to public. 
- Availability of supporting dataWe provide our data to readers and researchers whenever they need it.Competing interests

The authors have no competing interests to declare.

\section{- Funding}

This work was supported by Major bidding projects for Social Sciences in China\17ZDA327》.

- Authors' contributionsWang Pei conceived and funded the study and revised the ms. Liu Yuting carried out the study, analyzed the data and wrote the ms.- AcknowledgementsThanks a lot to all the hospitals that had participated in this survey.- Authors' information

Corresponding author: Pei WANG

Wenzhou Medical University, Wenzhouv, China;

Postal code: 325035

Faculty of Education, East China Normal University, 200062, Shanghai Postal address: 3663, Zhongshan North Road, Putuo District, Shanghai, China

Postal code: 200062

Email: wangpei1970@163.com

And the detailed information of authors is as follows:

\section{Yuting LIU}

Department of Psychology, Shanghai Normal University, Shanghai

Postal address: 100, Guilin Road, Xuhui District, Shanghai, China

Postal code: 200234

Tel: (86)2164324537

F-mail: liuyuting@163.com

\section{References}

1. Croker JE, Swancutt DR, Roberts MJ, Abel GA, Roland M, Campbell JL. Factors affecting patients' trust and confidence in GPs: evidence from the English national GP patient survey. BMJ open. 2013;3:e002762. 
2. Dong EH. The development and studies on patients' trust index system based on medical quality management (Doctoral dissertation). Shanghai Jiao Tong University. 2012 (in Chinese).

3. Xie QH, Lai J, He J, Song XY. Patients follow-up behavioral intention and its relationship with trust. Yi Xue Yu Zhe Xue. 2015;36:91-3. (in Chinese).

4. Birkhaüer J, Gaab J, Kossowsky J, Hasler S, Krummenacher P, Werner C, et al. Trust in the health care professional and health outcome: A meta-analysis. PLoS ONE. 2017;12:e0170988.

5. Liu YS. Analysis of the confidence problem between Chinese physicians and patients: cause and reconstructing strategy. Nan Jing Yi Ke Da Xue Xue Bao (She Hui Ke Xue Ban). 2012;12:282-85. (in Chinese).

6. Nie JB, Cheng Y, Zou X, Gong N, Tucker JD, Wong B, Kai BW. The vicious circle of medical mistrust in China: Perspectives of medical staff, institutional conflicts of interest, and building trust through medical professionalism. Dong Nan Da Xue Xue Bao (Zhe Xue She Hui Ke Xue). 2018;20:104-14. (in Chinese).

7. Mayer RC, Davis JH, Schoorman FD. An integrative model of organization trust. Acad Manag Rev. 1995;20:709-33.

8. Hall MA, Zheng B, Dugan E, Camacho F, Kidd KE, Mishra A, Balkrishnan R. Measuring Patients' Trust in their Primary Care Providers. Medical Care Research Review. 2002;59:293-318.

9. Pellegrino E, Thomasma D. Fidelity to trust in the Virtues in Medicine. New York: Oxford University Press; 1993.

10. Pearson SD, Raeke LH. Patients' trust in physicians: Many theories, few measures, and little data. J Gen Intern Med. 2000;15:509-13.

11. Thom DH, Hall MA, Pawlson LG. Measuring Patients' Trust in Physicians When Assessing Quality of Care. Health Aff. 2004;23:124-32.

12. Wang XJ, Wang C, Lv XK. Doctor-patient interpersonal trust: Concept, positive evolutionary process, and influential factors. Xin Li Ke Xue. 2016;39:1093-97. (in Chinese).

13. Lewis JD, Weigert A. Trust as a social reality. Soc Forces. 1985;63:967-85.

14. Wu L, Wan RX. An Analysis and the Mitigating Strategies of the Negative Effect of the "Asymmetric Relationship" between Doctors and Patients. Zhong Guo She Hui Xin Li Ping Lun. 2017;13:117-29. (in Chinese).

15. Mechanic D. Changing medical organization and the erosion of trust. Milbank Q. 1996;74:171-89.

16. Goold S. Money and trust: Relationships between patients, physicians, and health plans. J Health Polit Policy Law. 1998;23:688-95.

17. Sun LR, Wang P. Theory construction on the psychological mechanism of the harmonious doctorpatient relationship and its promoting technology. Xin Li Ke Xue Jin Zhan. 2019;27:951-64. (in Chinese).

18. Anderson LA, Dedrick RF. Development of the trust in physician scale: a measure to assess interpersonal trust inpatient-physician relationships. Psychol Rep. 1990;67:1091-100. 
19. Safran DG, Taira DA, Rogers WH, Kosinski M, Ware JE, Tarlov AR. Linking primary care performance to outcomes of care. J Fam Pract. 1998;47:213-20.

20. Kao AC, Green DC, Davis NA, Koplan JP, Cleary PD. Patients' trust in their physicians. J Gen Intern Med. 1998;13:681-86.

21. He FC. The research of public hospital patient's trust -- The hospital $Z$ in Shanghai as an example (master's thesis). Shanghai Jiao Tong University. 2015 (in Chinese).

22. Chen W, Bao QY, Li XY, Gong ZY. The influence of patient trust and participation behavior on doctorpatient trust. Yi Xue Yu Zhe Xue (A). 2017;38:21-4. (in Chinese).

23. Zhao $\mathrm{DH}$, Zhang ZZ. Changes in public trust in physicians: empirical evidence from China. Frontiers of Medicine. 2018;13:504-10.

24. Esteban O, Max R, Trust. OurWorldInData.org. 2016; https://ourworldindata.org/trust (accessed May 14, 2020).

25. Tam W. Health care reform and patients' trust in physicians in urban beijing. The China Quarterly. 2012;211:827-43.

26. Sun G, Chen YD, Zhou MY. Degree of trust in medical care and associated factors in community residents. Zhong Guo Quan Ke Yi Xue 2017; 20: 2003-06, 2011 (in Chinese).

27. Jiang N, Wu JQ, Dai L, Liu Y. A study on trust of non-medical students in medical staff. Zhong Guo Yi Xue Ren Wen. 2018;4:10-3. (in Chinese).

28. Sun YL. Analysis of the current situation and influencing factors of Doctor-patient trust from different perspectives of doctors and patients: Based on the investigation of six medical institutions in Beijing. Zhong Guo Yi Xue Lun Li Xue. 2018;31:94-100. (in Chinese).

29. Wang Z, Peng YC. Doctor-patient relationship, doctor-patient trust status and influencing factors in township health centers in Beijing. Zhong Hua Quan Ke Yi Xue. 2018;16:1690-93. (in Chinese).

30. Liu LP, Jiang SH. Patient-Centered Communication Mediates the Relationship between Health Information Acquisition and Patient Trust in Physicians: A Five-Year Comparison in China. Health Communication 2019; 1-10.

31. Shen SS, Wang SL, Li JY, Zhao J. Review of social trust mechanism and doctor-patient trust evaluation. Zhong Guo Yi Xue Lun Li Xue. 2017;30:1098-102. (in Chinese).

32. Dong Y. Research on influencing factors of doctor-patient knowledge transfer based on patient trust (master's thesis). Zhejiang University, Hangzhou. 2009 (in Chinese).

33. Bonds DE, Foley KL, Dugan E, Hall MA, Extrom P. An exploration of patients' trust in physicians in training. J Health Care Poor Underserved. 2004;15:294-306.

34. Zhou YY. An empirical study on the relationship between psychological contract performance and doctor-patient trust in social transition -- A case study of Taizhou city (master's thesis). Zhejiang Industry and Commerce university, Hangzhou. 2017 (in Chinese).

35. Zhang WH, Li JM. The investigation and analysis on the family economic conditions influence in patients families trust in doctors. Zhong Guo Mei Tan Gong Ye Yi Xue Za Zhi. 2017;20:753-56. (in 
Chinese).

36. Yang L, Wang YY, Huang YQ. A pilot of related factors of patients' understanding and trust in service providers. Zhong Guo Xin Li Wei Sheng Za Zhi. 2016;30:327-33. (in Chinese).

37. Pan JY, Zhao JB, Hou YF. Analysis of the current status of patients' trust in physicians and influencing factors. Guang Dong Yi Xue. 2017;38:941-43. (in Chinese ..

38. Xu SQ. Mediation effect of presupposed distrust between frustration in treatment and patient aggression (master's thesis). Southern Medical University, Guangzhou. 2017 (in Chinese).

39. Xie Z, Qiu ZQ, Zhang TH. Influence of patients' attitude on doctors' satisfaction with the doctorpatient relationship. Bei Jing Da Xue Xue Bao (Yi Xue Ban. 2009;41:141-43. (in Chinese ..

40. Chen YL, Mu YQ, Chen LM, Li SZ. Research and analysis of the influencing factors of the physicianpatient relationships. Chong Qing Yi Xue. 2012;41:277-78. (in Chinese).

41. Xu ZY, Xie Y, Ri HYZ, Wu Q. Status Quo and influence factors of doctor-patient trust. Zhong Guo Wei Sheng Zhi Liang Guan Li. 2016;23:49-52. (in Chinese).

42. Yang J, Lv ZF, Wang XY, Mo TX, Miao JN, et al. Comparative study on the doctor-patient trust level of urban and rural areas in Beijing. Zhong Guo Yi Yuan Guan Li. 2015;35:44-7. (in Chinese).

43. Jiang SJ, Wang WX, Zhao Y, Chen ML, Tian HG. Studying on the differences of trusting in doctors between outpatients and inpatients. Zhong Guo Wei Sheng Shi Ye Guan Li. 2018;35:888-90. 937 (in Chinese).

44. Zhou M, Zhao L, Campy KS, Wang S. Changing of China $\square$ s health policy and Doctor-Patient relationship: 1949-2016. Health Policy Technology. 2017;6:358-67.

45. Fang LJ. The Formation Process of Institutional Trust: A case study of new cooperative medical scheme. She Hui Xue Yan Jiu 2009; 130 - 48 (in Chinese).

46. Liu X, Mills A. Evaluating payment mechanisms: how can we measure unnecessary care? Health Policy Plann. 1999;14:409-13.

47. He D, Yu H, Chen Y. Equity in the distribution of ct and mri in china: a panel analysis. International Journal for Equity in Health. 2013;12:39.

48. Chen SM, He LY. Welfare loss of china's air pollution: how to make personal vehicle transportation policy. China Econ Rev. 2014;31:106-18.

49. Bai YH, Yan WP, Wang P, Chen YZ, Pang JY, Lu L, Zhu YW. Early warning mechanism of medical disputes with the perspective of psychology. Jie Fang Jun Yi Yuan Guan Li Za Zhi. 2015;22:14-7. (in Chinese).

50. Horton R. Offline. A barometer for trust in China. The Lancet. 2016;388:2222.

51. Liu W, Yuan HJ. The Internal logic of the doctor-patient relationship conflict and the refactoring of mutually beneficial doctor -- patient relationship. Kun Ming Li Gong Da Xue Xue Bao. 2017;17:4754. (in Chinese).

52. Zhang JC, Li SM, Yang SD, Zhang SB, Ke S, Liu D. Analysis of doctor-patient relationship from the perspective of trust and information asymmetry. Zhong Guo Yi Yao Zhi Nan. 2009;7:44-6. (in 
Chinese).

53. Twenge JM. Attitudes toward women, 1970-1995: A meta- analysis. Psychology of Women Quarterly. 1997;21:35-51.

54. Twenge JM, Konrath S, Foster JD, Campbell WK, Bushman B. Egos inflating over time: A crosstemporal meta-analysis of the narcissistic personality inventory. J Pers. 2008;76:875-902.

55. Xin ZQ, Chi LP. Cross-temporal meta-analysis: Linking social change to psychological development. Hua Dong Shi Fan Da Xue Xue Bao (Jiao Yu Ke Xue Ban). 2008;26:44-51. (in Chinese).

56. Moher D, Shamseer L, Clarke M, et al. Preferred reporting items for systematic review and metaanalysis protocols (PRISMA-P) 2015 statement. Systematic Review. 2015;4:1.

57. Hunter JE, Schmidt FL. Methods of meta-analysis: Correcting error and bias in research findings. London: Sage; 1990.

58. Twenge JM, Im C. Changes in the need for social approval, 1958-2001. J Res Pers. 2007;41:171-89.

59. Xin ZQ, Zhang M. Changes in Chinese Middle School Students' Mental Health (1992-2005): A crosstemporal meta-analysis. Xin Li Xue Bao. 2009;41:69-78. (in Chinese).

60. Yang R, You X, Zhang Y, Lian L, Feng W. Teachers' mental health becoming worse: The case of China. International Journal of Educational Development. 2019;70:102077.

61. Twenge JM. Birth cohort changes in extraversion: A cross- temporal meta- analysis, 1966-1993. Personality Individ Differ. 2001;30:735-48.

62. Wells G, Shea B, O'Connell D, Peterson J, Welch V, Losos M, Tugwell P. The Newcastle-Ottawa Scale (NOS) for assessing the quality of nonrandomised studies in meta-analyses. http://www.ohri.ca/programs/ clinical_epidemiology/oxford.asp (accessed May 14, 2020).

63. Wilson DB. Meta-analysis macros for SAS, SPSS, and Stata. 2010. http://mason. gmu.edu/ dwilsonb/ma.html (accessed May 14, 2020).

64. Tang $L$. The influences of patient's trust in medical service and attitude towards health policy on patient's overall satisfaction with medical service and sub satisfaction in china. Bmc Public Health. 2011;11:472-72.

65. Wang BL. Investigation on inpatients for physician trust in four hospitals of Liaoning Province (master's thesis). Chinese Medical Sciences University, Shenyang. 2014 (in Chinese).

66. Fang L, Zhang XW, Cao BH, Liu Q, Liu N, Zhang YL. Study on relationship between risk perception and doctor-patient trust of patients with chronic disease. Hu Li Yan Jiu. 2015;29:1991-93. (in Chinese).

67. Li YF, Wang XY, Guo R, Feng GS, Miao JN, et al. Study of doctor-patient trust and influence factors based on the view of patients. Zhong Guo Yi Yuan Guan Li. 2015;35:56-8. (in Chinese).

68. Xie QH, Wang YX, He J. Doctor-patient trust and the influencing factors from the perspective of patients. Xian Dai Yi Yuan. 2015;36:91-3. (in Chinese).

69. Wu Q. Study on influence factors and mechanism of patient engagement in healthcare (master's thesis). The Second Military Medical University, Shanghai. 2016 (in Chinese). 
70. Yang L, Zhang JL. The current status of patients' trust in doctors and its influencing factors--a case study of Nanchang City. Shang 2016; 92-93 (in Chinese).

71. Zhang JL. Research of the patient's trust in the doctors - Based on the general trust and interpersonal trust (master's thesis). Nanchang University. 2016 (in Chinese).

72. Zhang ZH. Investigation of ability trust and goodwill trust of patients in Zhejiang province based on the perspective of patient. Yi Xue Yu Zhe Xue. 2016;29:56-9. (in Chinese).

73. Zhao DH, Rao KQ, Zhang ZR. Patient trust in physicians. Chin Med J. 2016;129:814-18.

74. Cui MW. Research of doctor-patient trust based on four-quadrant model -- A case study of the second hospital of Tangshan (master's thesis). Southwest Jiao Tong University, Chengdu. 2017 (in Chinese).

75. Chi SX, Chen C. Does social capital benefit the trust of urban and rural residents in doctors? -- An empirical study based on CGSS2012 data. Ren Wen Za Zhi 2018; 112 - 21 (in Chinese).

76. Zhang R, Lu X, Wu W, Shang X, Liu M. Mature or Emerging? The Impact of Treatment-Related Internet Health Information Seeking on Patients' Trust in Physicians. International Journal of Environmental Research Public Health. 2018;15:1855-71.

77. Zhao DH, Zhao HY, Cleary PD. Understanding the determinants of public trust in the health care system in China: an analysis of a cross-sectional survey. Journal of Health Services Research Policy. 2018;24:37-43.

78. Gu LN, Deng JJ, Xu HW, Zhang SF, et al. The impact of contract service policy and doctor communication skills on rural patient-doctor trust relationship in the village clinics of three counties. BMC Health Services Research. 2019;19:187.

79. He W, Yun X, Chen X, Zhao HH. The Relationship between Patients' Trust, Medical Explicit Attitude and Implicit Attitude. Zhong Guo Lin Chuang Xin Li Xue Za Zhi. 2019;27:777-81. (in Chinese).

80. Li YW. Based on the consumer perspective of China's medical services to patients trust (master's thesis). Shijiazhuang University of Economics. 2013 (in Chinese).

81. Liu JT, Du X, Ma CS, Zhang P, Wu XS. Effect of the trust degree to doctor on clinical decision preference for patients with cardiovascular disease. Zhong Guo Yi Yao Dao Bao. 2014;11:135-38. (in Chinese).

82. Chen SF, Yin RF, Wei LY. Investigation and analysis on doctor-patient trust in Shandong Province. Zhong Guo Yi Xue Lun Li Xue. 2015;28:558-62. (in Chinese).

83. Liu JF. Study on the influencing factors of doctor-patient trust in Kunhua Hospital of Yunnan Province (master's thesis). Kunming University of Science and Technology. 2016 (in Chinese).

84. Bi ZR. A survey of doctor-patient trust status and trust restoration strategies (master's thesis). North China University of Science and Technology, Tangshan. 2018 (in Chinese).

85. Zhao JB, Zhu CH. Mediation effect of big five personality traits between patient aggression and doctor-patient trust. Zhong Guo Quan Ke Yi Xue. 2019;23:2850-55. (in Chinese). 
86. Twenge JM, Campbell WK. Age and birth cohort differences in self- esteem: A cross- temporal metaanalysis. Personality Social Psychology Review. 2001;5:321-44.

87. Twenge JM, Im C. Changes in the need for social approval, 1958-2001. J Res Pers. 2007;41:171-89.

88. Cohen J. Statistical Power Analysis for the Behavioral Sciences. New York: Lawrence Erlbaum Associates; 1988.

89. Hedges LV, Vevea JL. Fixed-and random-effects models in meta-analysis. Psychol Methods. 1998;3:486-504.

90. Higgins JPT, Thompson SG, Deeks JJ, Altman DG. Measuring inconsistency in meta-analyses. BMJ. 2003;327:557-60.

91. Borenstein M, Hedges LV, Higgins JP, Rothstein HR. Introduction to meta-analysis. New York: Wiley Press; 2009.

92. Rothstein HR, Sutton AJ, Borenstein M. Publication bias in meta-analysis. In: Rothstein HR, Sutton AJ, Borenstein M, editors. Publication bias in meta-analysis: Prevention, assessment and adjustments. Chichester: Wiley; 2005. pp. 1-7.

93. Egger M, Smith GD, Schneider M, Minder C. Bias in meta-analysis detected by a simple, graphical test. BMJ. 1997;315:629-34.

94. Duval S, Tweedie R. Trim and fill: A simple funnel-plot-based method of testing and adjusting for publication bias in meta-analysis. Biometrics. 2000;56:455-63.

95. Wu P, Liu HS. Association between moral reasoning and moral behavior: A systematic review and meta-analysis. Xin Li Xue Bao. 2014;46:1192-207. (in Chinese).

96. An N. Content analysis of the media image of doctors based on data from 2011-2015 on Sina.com.cn (master's thesis). Chongqing University. 2006 (in Chinese).

97. Wang XJ, Wang J. A frame analysis of Doctor-patient disputes reporting and its influence on doctorpatient trust: Taking people's Daily and Jiankang Bao as Examples. Nan Jing Shi Fan Da Xue Xue Bao (She Hui Ke Xue) 2018; 215: 75-84 (in Chinese).

98. Luo GH. Impacts of media's untrue report on doctor-patient conflicts. Yi Xue Yu She Hui. 2016;29:534. (in Chinese).

99. Ma TJ. Public opinion presentation of doctor-patient conflict news in internet media-- A case study of the "Gauze Door". Xin Wen Yan Jiu Dao Kan. 2016;7:34. (in Chinese).

100. Li FH. The Issue Characteristics and Construction of China's Doctor-Patient Relationship Report in the New Media Environment--Based on the Analysis of the Boy Falling Well in Yi County, Hebei. Xin Wen e Jia 2017; 37-40 (in Chinese).

101. Xin ZQ. Marketization and interpersonal trust decline in China. Advances in Psychological Science. 2019;27:1951-66.

102. Chai MQ, Wang J. An exploration of formation mechanism of doctor-patient trust crisis: from the perspective of intergroup relationship. Nan Jing Shi Fan Da Xue Xue Bao (She Hui Ke Xue) 2016; 117 -22 (in Chinese). 
103. Ye X. Study on the process of construction of the doctor-patient relationship based on interpersonal communication-- cases study of doctor-patient dialogues between China and the United States (Doctoral dissertation). Wuhan University. 2015 (in Chinese).

104. Sun FC. Medical Humanism: The ethical root of doctor-patient harmony -- "Doctors are humans". Zhong Guo Yi Xue Lun Li Xue. 2019;32:1103-08. (in Chinese).

105. Goldizen FC. From SARS to avian influenza: the role of international factors in china's approach to infectious disease control. Annals of Global Health. 2016;82:180-88.

106. Koh L, Glaetzer C, Li SC, Zhang M. Health technology assessment, international reference pricing, and budget control tools from china's perspective: what are the current developments and future considerations? Value Health Reg Issues. 2016;9:15-21.

107. McLaughlin MM, Simonson L, Zou X, Ling L, Tucker JD. African Migrant Patients' Trust in Chinese Physicians: A Social Ecological Approach to Understanding Patient-Physician Trust. PLoS ONE. 2015;10:e0123255.

108. Fritz HL, Helgeson VS. Distinctions of unmitigated communion from communion: Self-neglect and overinvolvement with others. J Pers Soc Psychol. 1998;75:121-40.

109. Amanatullah ET, Morris MW, Curhan JR. Negotiators who give too much: Unmitigated communion, relational anxieties, and economic costs in distributive and integrative bargaining. J Pers Soc Psychol. 2008;95:723-38.

110. Kunovich RM. Social structural position and prejudice: an exploration of cross-national differences in regression slopes. Soc Sci Res. 2004;33:20-44.

111. Schnittker J. Social distance in the clinical encounter: Interactional and sociodemographic foundations for mistrust in physicians. Social Psychology Quarterly. 2004;67:217-35.

112. Borgonovi F. The relationship between education and levels of trust and tolerance in Europe. The British Journal of Sociology. 2012;63:146-67.

113. Zeng QQ, Chang C, Jiang Y, Yuan YF, et al. Association between health literacy and utilization of basic public health services among urban elderly residents. Zhong Guo Jian Kang Jiao Yu. 2014;30:771-76. (in Chinese).

114. Eiglier P, langeard E. A New Approach to Service Marketing. 1977. In P. Eiglier, E. Langeard, C. H. Lovelock, J. E. G. Bateson \& R. F. young, editors, Marketing Consumer Services: New Insights (pp.3358), Cambridge, MA: Marketing Science Institute.

115. Sheppard VB, Zambrana RE, O'Malley AS. Providing health care to low-income women: a matter of trust. Fam Pract. 2004;21:484-91.

116. Johnson DW, Johnson RT. New developments in social interdependence theory. Genet Soc Gen Psychol Monogr. 2005;131:285-358.

117. Huo RM, Ma JH, He Q, Wang WD. The influence of dependence structure on trust: Based on interdependence theory. Xin Li Xue Tan Xin. 2017;37:178-84. (in Chinese). 
Figures
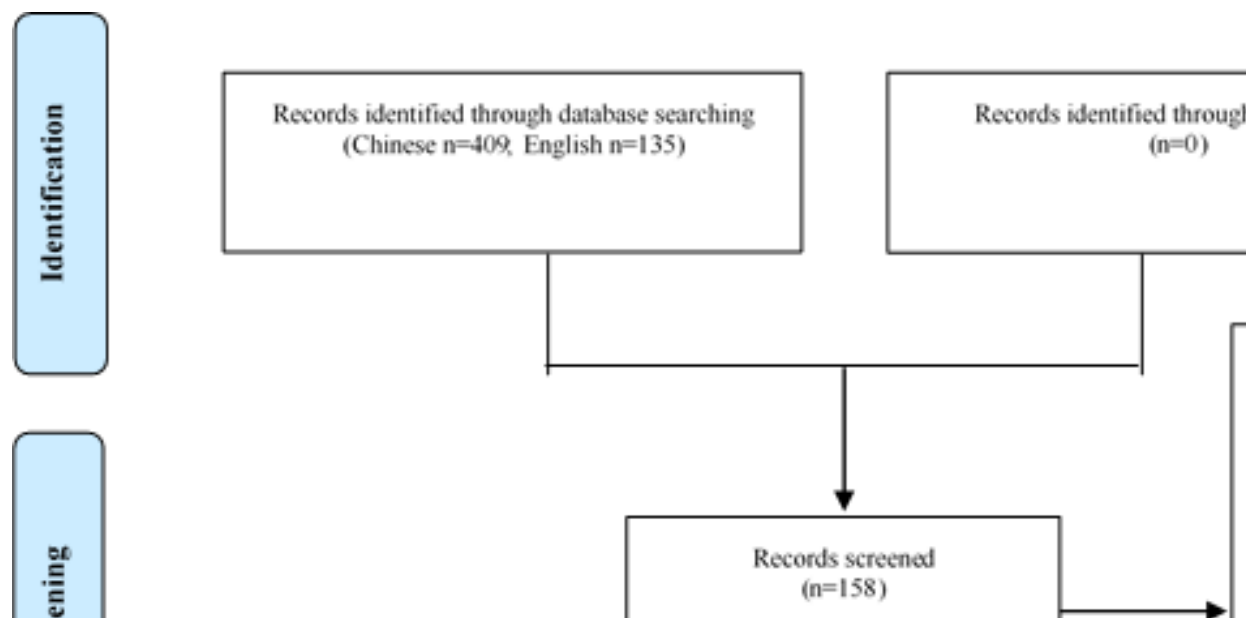

Records excluded by title and abstract $(\mathrm{n}=381)$

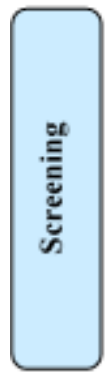

Qualitative study/ Theory / Review: 272

-Conferences/newspapers /books : 26

-Case study : 8

-Duplicate : 6

-Not studying Chinese : 10

-Research content does not match : 59
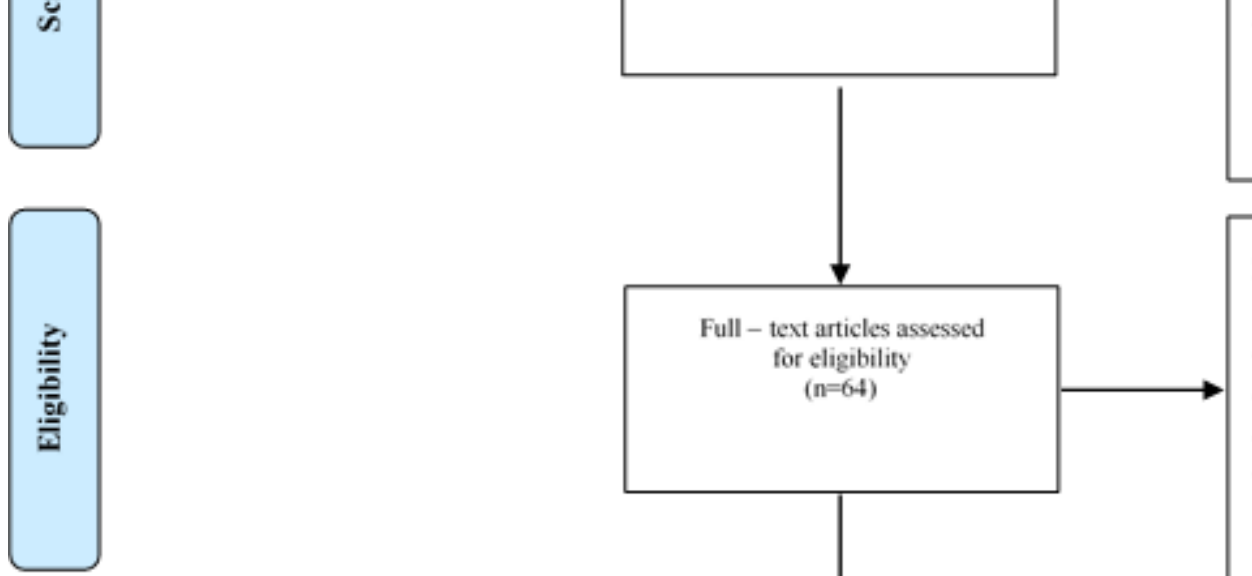

Records excluded after full - text review $(n=96)$

-Trustee is a doctor: 22

-Institutional Trust -5

-Trust is an independent or intermediary variable :52

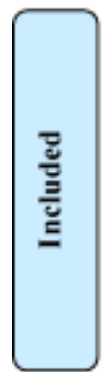

Studies included in analysis $(n=40)$

Records excluded by data ( $n=24$ )

-No appropriate statistical data $: 24$

$$
(\mathrm{n}=)
$$

\section{Figure 1}

Flow of literature through the review 


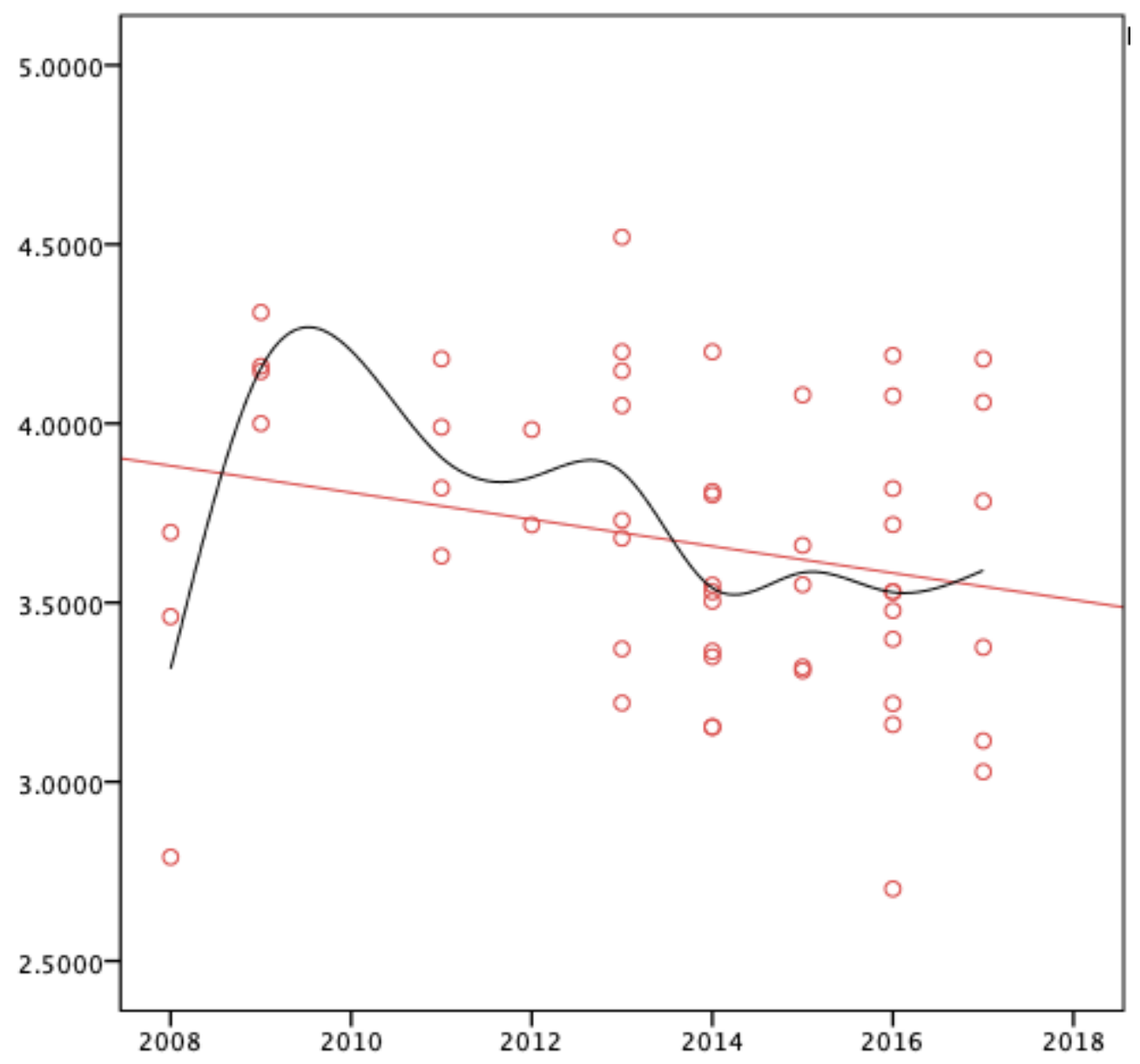

Figure 2

Correlation between total trust scores and year of data collection 


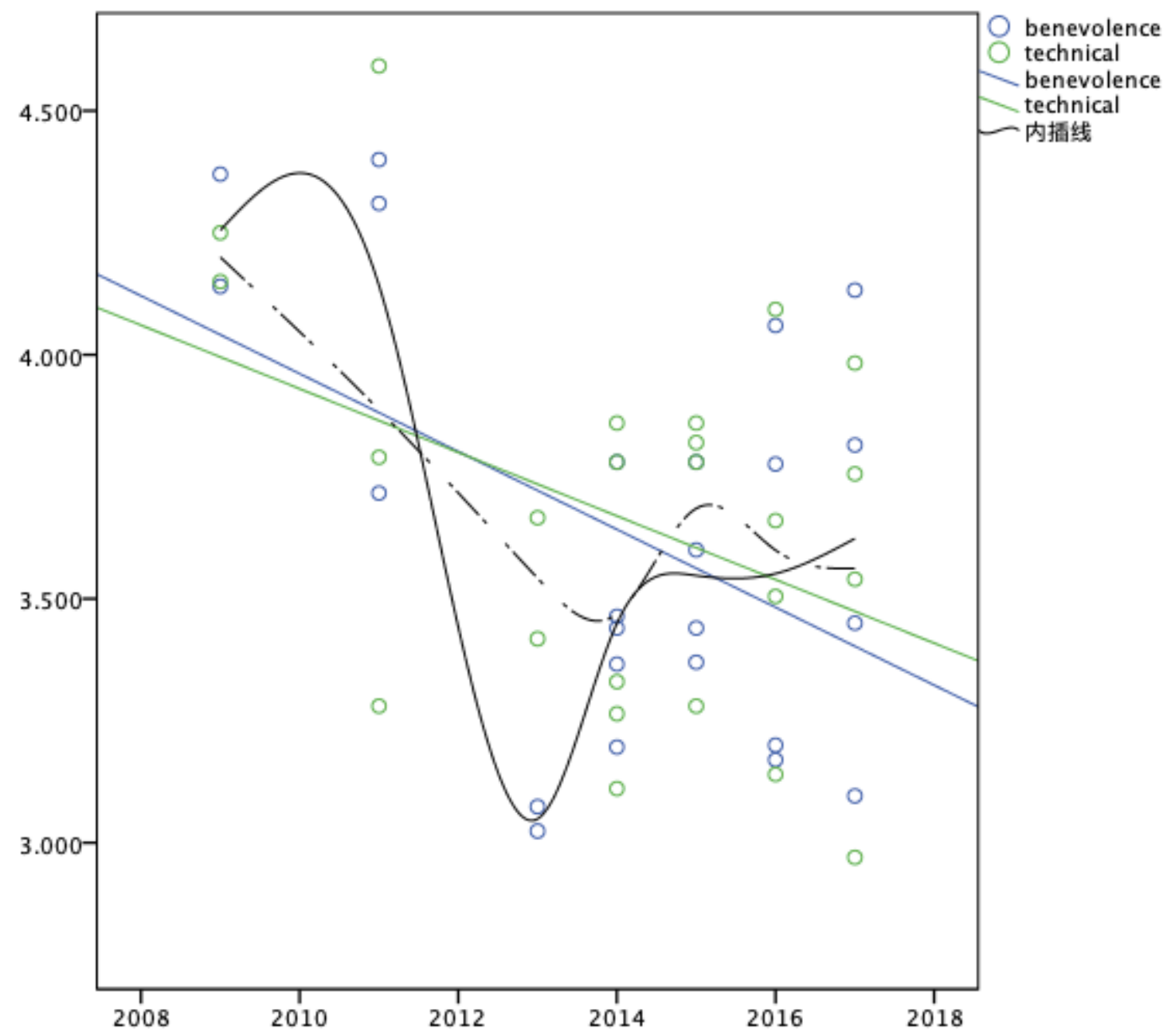

Figure 3

Correlation between benevolence trust, technical trust scores and year of data collection 


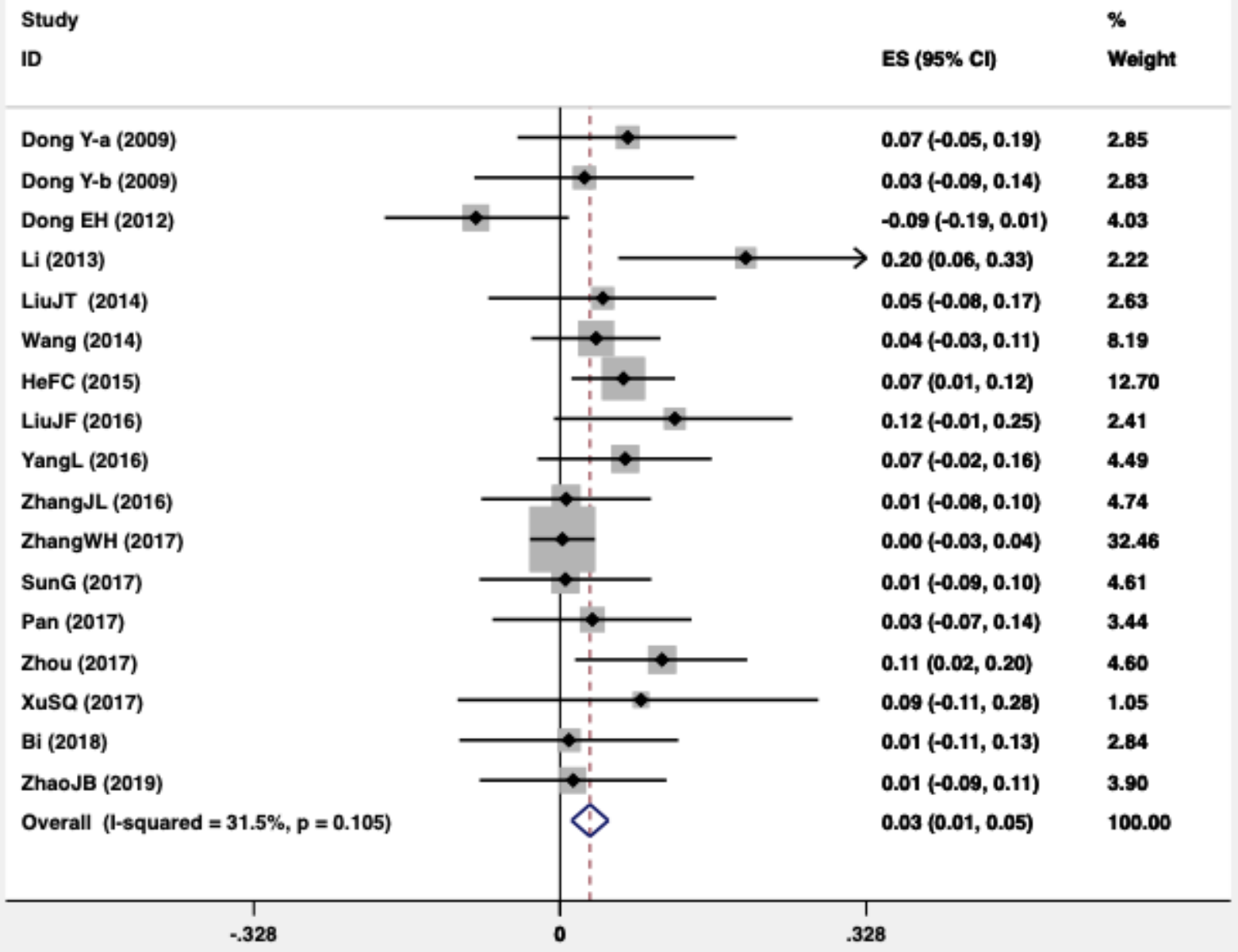

Figure 4

Forest plot showing associations between patient's trust and gender 


\begin{tabular}{|c|c|c|}
\hline Study & & $\%$ \\
\hline ID & ES $(95 \% \mathrm{Cl})$ & Weight \\
\hline Dong Y-b (2009) & $0.14(0.03,0.26)$ & 4.94 \\
\hline Dong EH (2012) & $-0.06(-0.16,0.04)$ & 5.96 \\
\hline Li (2013) & $0.12(-0.02,0.25)$ & 3.92 \\
\hline LiuJT (2014) & $0.05(-0.07,0.17)$ & 4.59 \\
\hline Wang (2014) & $0.11(0.04,0.18)$ & 8.57 \\
\hline Chen (2015) & $0.14(0.05,0.23)$ & 6.83 \\
\hline HeFC (2015) & $0.07(0.01,0.12)$ & 9.92 \\
\hline LiuJF (2016) & $0.21(0.09,0.33)$ & 4.50 \\
\hline YangL (2016) & $0.05(-0.05,0.14)$ & 6.36 \\
\hline ZhangJL (2016) & $0.11(0.02,0.20)$ & 6.64 \\
\hline ZhangWH (2017) & $0.01(-0.02,0.05)$ & 12.17 \\
\hline SunG (2017) & $0.08(-0.01,0.17)$ & 6.51 \\
\hline Pan (2017) & $0.05(-0.05,0.16)$ & 5.47 \\
\hline Zhou (2017) & $0.12(0.03,0.21)$ & 6.48 \\
\hline XusQ (2017) & $0.10(-0.09,0.29)$ & 2.28 \\
\hline $\mathrm{Bi}(2018)$ & $0.08(-0.03,0.20)$ & 4.87 \\
\hline Overall ( 1 -squared $=50.3 \%, p=0.011$ ) & $0.08(0.05,0.11)$ & 100.00 \\
\hline NOTE: Weights are from random effects analysis & & \\
\hline $\begin{array}{c}1 \\
-.334\end{array}$ & & \\
\hline
\end{tabular}

\section{Figure 5}

Forest plot showing associations between patient's trust and age 
Study

ID
$\%$

ES $(95 \% \mathrm{Cl}) \quad$ Weight

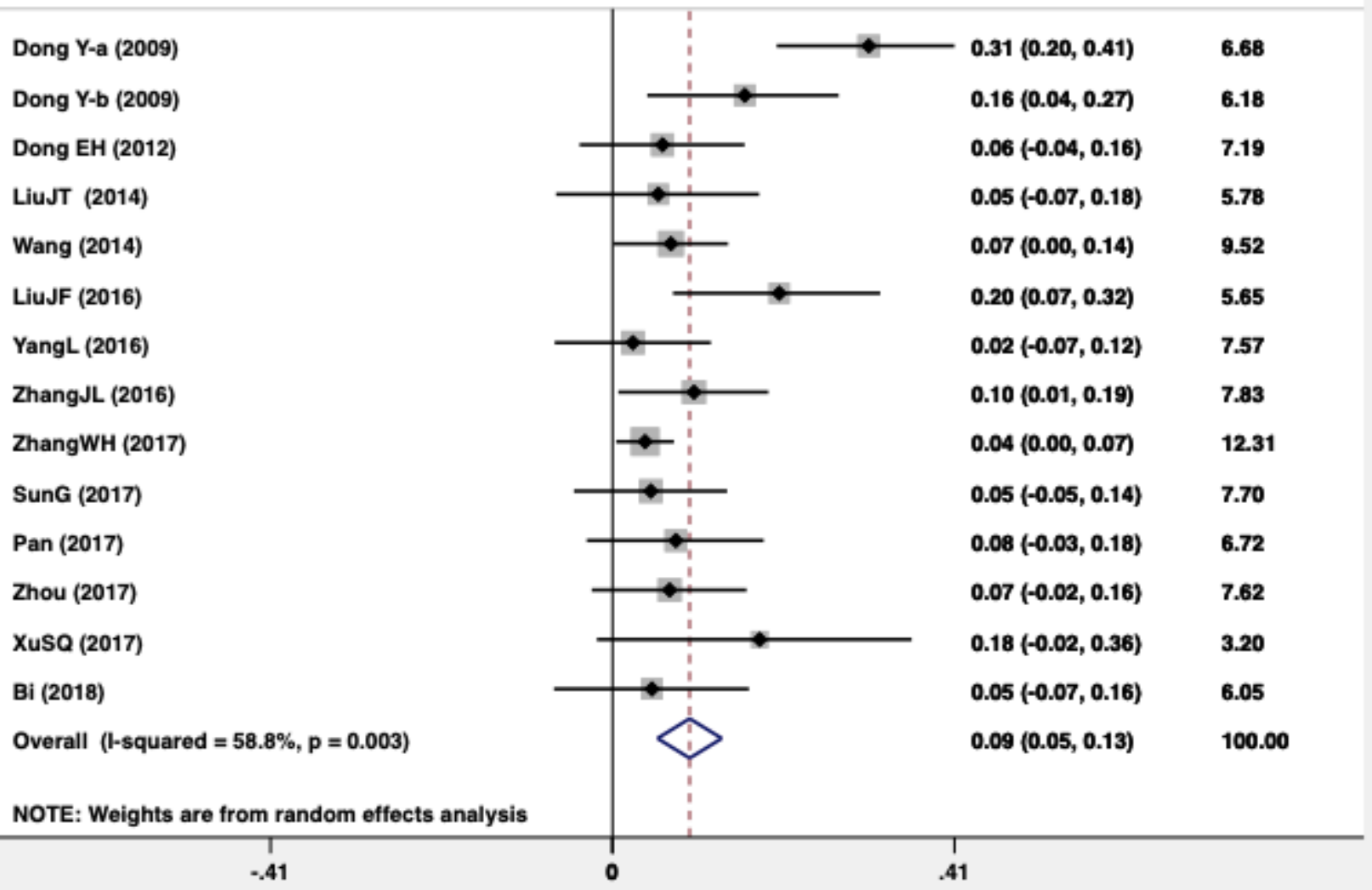

Figure 6

Forest plot showing associations between patient's trust and education 